\title{
Relationship between growth and intelligence quotient in children with Down syndrome
}

\author{
Anna Kłosowska ${ }^{1} \wedge$, Agnieszka Kuchta $^{2} \wedge$, Agnieszka Ćwiklińska ${ }^{2}$, Kornelia Sałaga-Zaleska ${ }^{2}$, \\ Maciej Jankowski ${ }^{2} \wedge$, Przemysław Kłosowski ${ }^{3} \wedge$, Arkadiusz Mański ${ }^{4}$, Michał Zwiefka ${ }^{4} \wedge$, \\ Paulina Anikiej-Wiczenbach ${ }^{4} \wedge$, Jolanta Wierzba ${ }^{5} \wedge$
}

${ }^{1}$ Department of Pediatrics, Hematology and Oncology, Medical University of Gdańsk, Gdańsk, Poland; ${ }^{2}$ Department of Clinical Chemistry, Medical University of Gdańsk, Gdańsk, Poland; ${ }^{3}$ Department of Endocrinology and Internal Medicine, Medical University of Gdańsk, Gdańsk, Poland; ${ }^{4}$ Psychological Counselling Centre of Rare Genetic Diseases, University of Gdańsk, Gdańsk, Poland; ${ }^{5}$ Department of Internal and Pediatric Nursing, Institute of Nursing and Midwifery, Medical University of Gdańsk, Gdańsk, Poland

Contributions: (I) Conception and design: A Kłosowska, A Kuchta; (II) Administrative support: J Wierzba, M Jankowski; (III) Provision of study materials or patients: A Kłosowska, J Wierzba; (IV) Collection and assembly of data: A Kłosowska, A Kuchta, A Mański, P Anikiej-Wiczenbach, M Zwiefka; (V) Data analysis and interpretation: A Kłosowska, A Kuchta, P Kłosowski, A Ćwiklińska, K Sałaga-Zaleska; (VI) Manuscript writing: All authors; (VII) Final approval of manuscript: All authors.

Correspondence to: Anna Kłosowska, MD. Department of Pediatrics, Hematology and Oncology, Medical University of Gdańsk, Dębinki 7, 80-211, Gdańsk, Poland. Email: anna.klosowska@gumed.edu.pl.

Background: The relationship between intelligence quotient (IQ) and somatic development, especially growth, has been demonstrated in various groups of children. Down syndrome (DS) is characterized by short stature, overweight, and cognitive impairment. The objective of our work was to assess whether anthropometric measurements [weight, height, body mass index (BMI)] of children with DS correlate with their IQ. The results of the study may be valuable for this population in the light of increasing access to growth hormone therapy (GHT) in various genetic syndromes with short stature. Based on previous studies on children, we hypothesized that a link exists between IQ and somatic development, particularly growth.

Methods: This cross-sectional study included 40 children with DS, who were aged 9-18 years. The studied population was selected from the registry of the Genetic Clinic at the University Clinical Center in Gdańsk (Poland). Anthropometric measurements (weight and height) were taken for all the children, and their BMI was determined using these data. The obtained results were plotted on charts for children with DS. The IQ of the children was assessed using the Stanford Binet Intelligence Scale, Fifth Edition. The correlations between IQ and anthropometric data were analyzed using univariate correlation and multiple regression analyses.

Results: The results showed that full-scale, verbal, and nonverbal IQ correlated with height percentile ( $\mathrm{P}=0.03, \mathrm{P}=0.02$, and $\mathrm{P}=0.04$, respectively), but not with weight $(\mathrm{P}=0.26, \mathrm{P}=0.19$, and $\mathrm{P}=0.61$, respectively) or $\mathrm{BMI}(\mathrm{P}=0.6, \mathrm{P}=0.5$, and $\mathrm{P}=0.72$, respectively). In multiple linear regression analysis, height percentile remained as an independent determinant of the IQ results after adjusting for birth weight, hypothyroidism with L-thyroxine replacement therapy, and congenital cardiac defect $(\beta=0.48, \mathrm{P}=0.018)$.

Conclusions: The results of our study suggest an association between growth and IQ in children with DS. The presented findings may be valuable for improving access to GHT for populations with genetic syndromes characterized by short stature. However, these should be confirmed by further research with a longitudinal sample of children with DS.

\footnotetext{
^ ORCID: Anna Kłosowska, 0000-0002-4378-5683; Agnieszka Kuchta, 0000-0003-2264-1442; Agnieszka Ćwiklińska, 0000-0003-14263744; Kornelia Sałaga-Zaleska, 0000-0001-8238-1836; Maciej Jankowski, 0000-0003-4540-6955; Przemysław Kłosowski, 0000-0001-96632755; Arkadiusz Mański, 0000-0003-3154-9656; Michał Zwiefka, 0000-0002-0036-0079; Paulina Anikiej-Wiczenbach, 0000-0002-7090211X; Jolanta Wierzba, 0000-0003-0290-1243.
} 
Keywords: Down syndrome (DS); intelligence quotient (IQ); growth; intellectual disability

Submitted Sep 03, 2021. Accepted for publication Jan 18, 2022.

doi: $10.21037 /$ tp-21-424

View this article at: https://dx.doi.org/10.21037/tp-21-424

\section{Introduction}

Down syndrome (DS) is one of the most common intellectual disabilities caused by genetic factors (1). It affects approximately one in every 1,000 live births in Europe and one in every 792 live births in the USA (2). In the last 50 years, the life expectancy of DS patients has increased significantly, which can be attributed not only to advances in cardiac surgery but also to improved overall patient care and healthcare guidelines $(3,4)$. In addition to other dysmorphic features, short stature is commonly found in patients with DS (5). In this population, growth retardation commences prenatally and lasts throughout life. The average final height of males and females with DS falls below the third percentile on the growth charts for height of the general population $(6,7)$. DS is associated with various health conditions, including congenital heart defects, thyroid disease, hearing loss, gastrointestinal tract abnormalities, diabetes mellitus, celiac disease, which may additionally affect growth and intellectual development (8). Moreover, compared to healthy children, those with DS are more likely to be overweight or obese, with studies indicating that the combined prevalence of overweight and obesity varies between $23 \%$ and $70 \%$ (9). The degree of cognitive impairment in the DS population may be mild [intelligence quotient (IQ) 50-70], moderate (IQ 35-50), or severe (IQ 20-35). The majority of individuals with DS exhibit moderate intellectual disability, although significant differences have been noted within this population. These differences emerge early in childhood and have an impact on various characteristics including visuospatial and verbal memory, global and local processing, and language skills (10).

The relationship between growth and cognitive outcomes has been investigated in different groups of children. The Newcastle Thousand Families Study including a cohort of 733 children aged 9-13 years showed a positive association between IQ and standardized height (11). A study on 127 Jamaican children aged 11-12 years showed that children with growth restriction performed significantly poorer than nongrowth-restricted children in a wide range of cognitive tests (12). A recent meta-analysis and systematic review indicated that children who had intrauterine growth restriction and were small for gestational age (SGA) exhibited poorer cognitive function during the first 12 years of life compared to children who were appropriate for gestational age (13). Moreover, a study on 1,088,980 Swedish children showed that infants born SGA at term had an increased risk of poor school performance. The risk increased with the severity of SGA and started to decrease after adequate catch-up growth, which suggests that the course of growth during childhood and final height may also influence the intellectual development of children (14). To our knowledge, no studies have so far investigated the relationship between growth and cognition in populations with genetic syndromes with short stature, such as DS. Therefore, in this study, we aimed to assess whether the differences in anthropometric measurements, such as weight, height, and body mass index (BMI), between children with DS correlated with the differences in their intellectual and cognitive functioning. We present the following article in accordance with the STROBE reporting checklist (available at https://tp.amegroups.com/article/ view/10.21037/tp-21-424/rc).

\section{Methods}

We used a cross-sectional study design to compare the height, weight, and BMI of children with DS with their IQ, as all the parameters were measured once and in a short period of time. The participants were selected based on the inclusion and exclusion criteria set for the study.

\section{Participants}

All participants were patients who were regularly attending the Genetic Clinic at the University Clinical Center in Gdańsk (Poland). Between 2016 and 2019, the Clinic's registry contained data of 58 patients with DS, aged 9-19 years, whose parents had agreed to be contacted by phone for research conducted in the University Clinical Center. From this group, 40 patients (Caucasian; 17 boys, 23 girls) fulfilled the study's inclusion criteria and agreed 
to participate. Eight parents refused the participation of their children due to lack of time, while two parents refused to come twice as they live too far from the clinic. Eight patients did not meet the inclusion criteria. Participants came from the Gdańsk metropolitan area and from smaller towns and villages in the surrounding area. Recruitment and data collection was carried out from April 2016 to May 2019.

The inclusion criteria were as follows: (I) trisomy of chromosome 21; (II) age between 9 and 19 years; and (III) willingness to cooperate and provide signed informed consent. The exclusion criteria were as follows: (I) diagnosis of mosaic DS or translocation DS; (II) birth weight below 1,500 g; (III) presence of severe associated diseases affecting energy balance or growth (including diabetes, celiac disease, and renal failure); (IV) decompensated thyroid disease (thyroid-stimulating hormone level $<0.34$ or $>4.94 \mu \mathrm{U} / \mathrm{mL}$ ); (V) history of cancer or intestinal anomalies requiring bowel resection; or (VI) ongoing medical intervention. The study was conducted in accordance with the Declaration of Helsinki (as revised in 2013). All participants and their parents/guardians provided written informed consent to participate in the study. All study procedures were reviewed and approved by the Independent Bioethics Committee for Scientific Research at the Medical University of Gdańsk (No. NKBBN/105-96/2016).

\section{Procedures}

Anthropometric measurements were taken for each subject during a follow-up visit at the Genetic Clinic at the University Clinical Center in Gdańsk. The weight of the participants in their underwear was measured on a mechanical column scale (Seca 711), and their height was measured using a telescopic stadiometer (Seca 220). To reduce the possibility of measurement error, all participants were measured by a single trained anthropometrist. The BMI of the participants was determined by dividing their height (in meters) squared by weight (in kilograms). The following were identified as potentially confounding variables: age, gender, birth weight, hypothyroidism requiring L-thyroxine replacement therapy (tRT), and congenital cardiac defect requiring open-heart surgery. To eliminate the influence of age and gender, we assessed weight, height, and BMI of participants using the growth charts for DS $(15,16)$. The remaining three variables were included in the analysis. Excess adiposity was identified using the national BMI charts (7). Overweight was defined as a BMI between 85 th and 95 th percentile, and obesity as a
BMI of 95 th percentile or above.

The intellectual and cognitive functioning of the participants was assessed using the Stanford Binet Intelligence Scale, Fifth Edition (SB-V), in the Institute of Psychology of the University of Gdańsk. This assessment was carried out on a separate day that was convenient for the participant. Prior to the assessment, it was ensured that each participant was rested and in good condition to take up the test. The SB-V scale has two subtests: verbal and nonverbal. Each subtest assesses the following five factors: fluid reasoning, knowledge, quantitative reasoning, visualspatial processing, and working memory (17). The Polish version of $\mathrm{SB}-\mathrm{V}$ is based on a representative sample of 2,350 children. Several confounding variables, such as age, gender, place of residence, and socioeconomical status, were considered in the sample selection process. The Composite Score and each measured scale/factor showed good reliability (Composite Score $\alpha=0.98$; nonverbal $\alpha=0.95$; verbal $\alpha=0.96$; factors $\alpha=0.88-0.91$ ) (18). Both anthropometric examination and the SB-V assessment were successfully conducted on all the studied participants.

\section{Statistical analysis}

Statistical analysis was performed using Statistica 13.3 Software. Categorical variables were expressed as number and percentage, and analyzed using Pearson chi-squared test, while continuous variables were expressed as mean \pm standard deviation or median with 25 th -75 th percentile (interquartile range). The distribution of variables was tested using the Shapiro-Wilk test. The differences between more than two groups were assessed using the KruskalWallis one-way analysis of variance. Univariate correlations were evaluated using standardized Spearman's test, and multilinear regression using standardized $\beta$ coefficients. Before regression analyses, logarithmic transformations were applied, when appropriate, to approach Gaussian distribution. P values below 0.05 were considered statistically significant.

\section{Results}

The demographic, anthropometric, and clinical data of the participants are presented in Table 1. The results of the SB-V assessment are presented in Table 2. The SB-V assessment allowed dividing the studied population into four groups depending on the degree of cognitive impairment. Children who scored less than 20 in the assessment were 
Table 1 Demographic, anthropometric, and clinical data of participants

\begin{tabular}{|c|c|}
\hline Variables & Values \\
\hline \multicolumn{2}{|l|}{ Demographic parameters } \\
\hline $\mathrm{N}$ & 40 \\
\hline Age, years & $14.4 \pm 2.5$ \\
\hline \multicolumn{2}{|l|}{ Gender, n (\%) } \\
\hline Male & $17(42.5)$ \\
\hline Female & $23(57.5)$ \\
\hline \multicolumn{2}{|l|}{ Comorbid diseases } \\
\hline$\%$ AVC & 35.0 \\
\hline$\%$ VSD/ASD & 12.5 \\
\hline$\%$ PDA & 2.5 \\
\hline$\%$ CoA & 2.5 \\
\hline \% Hypothyroidism & 87.5 \\
\hline$\%$ Hyperthyroidism & 2.5 \\
\hline \multicolumn{2}{|l|}{ Anthropometric measures } \\
\hline Height, cm & $147.00 \pm 11.56$ \\
\hline Height for age percentile on DS growth chart, $\mathrm{cm}$ & $61.40 \pm 29.96$ \\
\hline Weight, kg & $48.76 \pm 13.02$ \\
\hline Weight for age percentile on DS weight chart, kg & $45.70 \pm 28.11$ \\
\hline $\mathrm{BMI}, \mathrm{kg} / \mathrm{m}^{2}$ & $22.32 \pm 4.58$ \\
\hline BMI for age percentile on DS BMI chart, $\mathrm{kg} / \mathrm{m}^{2}$ & $38.15 \pm 25.80$ \\
\hline
\end{tabular}

Continuous values are presented as mean \pm standard deviation. ASD, atrial septal defect; AVC, atrioventricular canal; BMI, body mass index; CoA, coarctation of the aorta; DS, Down syndrome; PDA, patent ductus arteriosus; VSD, ventricular septal defect. classified as profound intellectually disabled, those with scores between 20 and 34 as severely intellectually disabled, those with scores between 35 and 49 as moderately intellectually disabled, and those who scored between 50 and 69 as mildly intellectually disabled. The characteristics of participants in the individual groups are presented in Table 3. Univariate correlation analysis indicated that the IQ results (full scale, verbal, and nonverbal) of the participants significantly correlated with their height percentile, but not with other anthropometric data (Table 4). In multiple linear regression analysis, height percentile remained as an independent determinant of the IQ results after adjusting for birth weight, hypothyroidism with tRT, and congenital cardiac defect (Table 5).

The majority of participants obtained the lowest score for all five individual factors of the SB-V scale (floor effect). A comparison of the height percentile of children with the lowest score in the psychological test and those with higher scores is shown in Figure 1. A statistically significant correlation with height percentile was observed for 4 of the 5 factors of the subtest (fluid reasoning, knowledge, quantitative reasoning, and working memory), but not for visual-spatial processing.

\section{Discussion}

The results of this study indicate that the height percentile of children with DS correlates with their IQ. This correlation can be observed in terms of general, verbal, and nonverbal IQ as well as four of the five factors of the SB-V subtest. We did not find any correlation between the IQ and the BMI of the participants. To our knowledge, no similar

Table 2 Results of the assessment using Stanford Binet Intelligence Scale, Fifth Edition

\begin{tabular}{lccc}
\hline Parameter & Median & Interquartile range & Minimum-maximum \\
\hline Full scale IQ & 23 & $10-35$ & $10-60$ \\
Verbal IQ & 42 & $42-45$ & $40-61$ \\
Nonverbal IQ & 43 & $39-49$ & $37-65$ \\
Fluid reasoning & 45 & $45-51$ & $45-64$ \\
Knowledge & 51 & $48-55$ & $48-74$ \\
Quantitative reasoning & 48 & $48-51$ & $48-62$ \\
Visual-spatial processing & 47 & $47-53$ & $47-67$ \\
Working memory & 44 & $44-56$ & $44-69$ \\
\hline
\end{tabular}

$\mathrm{IQ}$, intelligence quotient. 
Table 3 Characteristics of the IQ groups

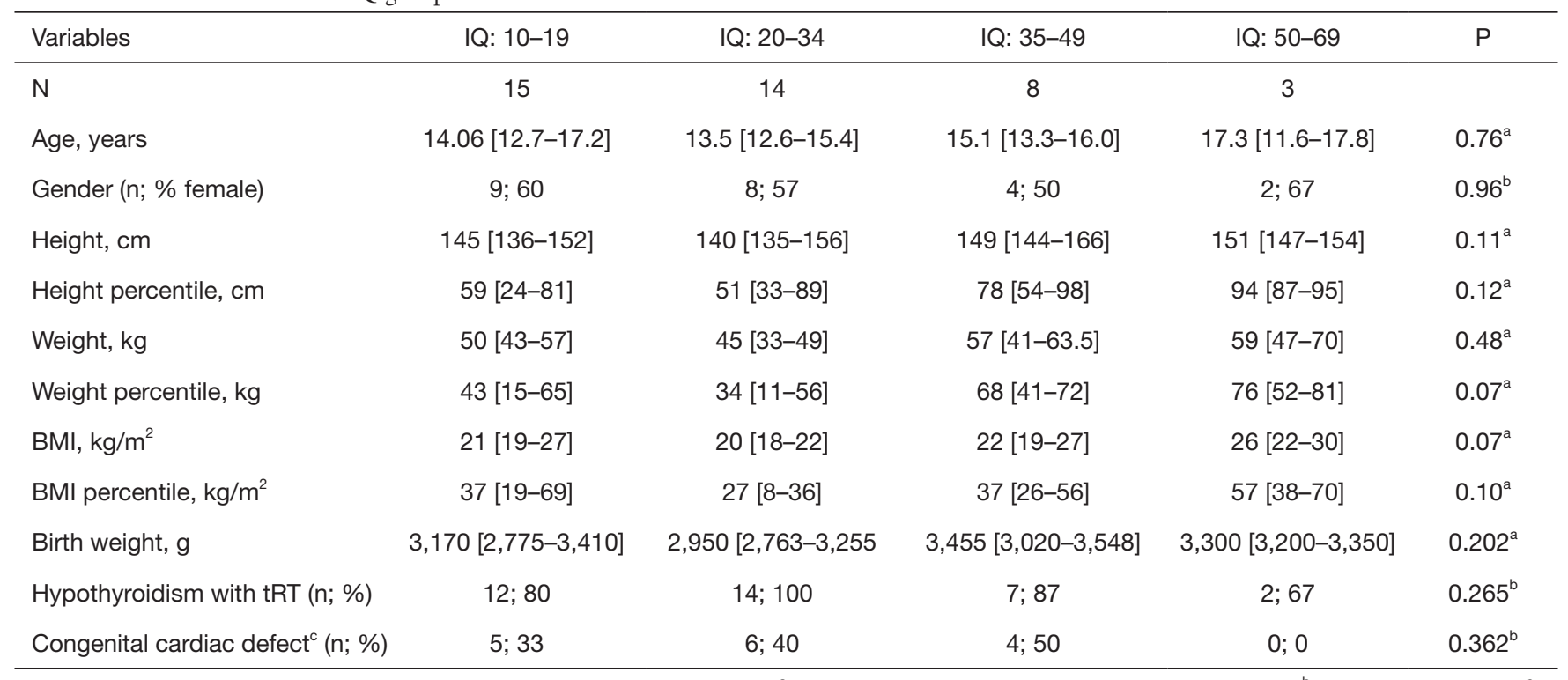

Continuous values are presented as median [25th-75th percentile]. ${ }^{a}$, Kruskal-Wallis one-way analysis of variance; ${ }^{\mathrm{b}}$, Chi-squared test; ${ }^{\mathrm{b}}$, requiring open-heart surgery. ASD, atrial septal defect; AVC, atrioventricular canal; BMI, body mass index; IQ, intelligence quotient; tRT, L-thyroxine replacement therapy; VSD, ventricular septal defect.

Table 4 Univariate correlation between anthropometric data and SB-V results

\begin{tabular}{|c|c|c|c|c|c|c|}
\hline Parameter & \multicolumn{2}{|c|}{ Height percentile } & \multicolumn{2}{|c|}{ Weight percentile } & \multicolumn{2}{|c|}{ BMI percentile } \\
\hline Full scale IQ & 0.352 & 0.03 & 0.183 & 0.26 & 0.086 & 0.60 \\
\hline Verbal IQ & 0.355 & 0.02 & 0.211 & 0.19 & 0.108 & 0.50 \\
\hline Nonverbal IQ & 0.323 & 0.04 & 0.082 & 0.61 & -0.058 & 0.72 \\
\hline Knowledge & 0.355 & 0.03 & 0.063 & 0.70 & -0.133 & 0.41 \\
\hline Quantitative reasoning & 0.589 & $<0.001$ & 0.474 & 0.002 & 0.269 & 0.09 \\
\hline Visual-spatial processing & 0.286 & 0.07 & 0.254 & 0.01 & 0.213 & 0.19 \\
\hline Working memory & 0.396 & 0.01 & 0.265 & 0.10 & 0.104 & 0.52 \\
\hline
\end{tabular}

R, Spearman's correlation coefficient. BMI, body mass index; IQ, intelligence quotient; SB-V, Stanford Binet Intelligence Scale, Fifth Edition.

studies have so far been performed on children with DS, although the relationship between growth and intelligence had been widely investigated in the general population. In 1892, Porter conducted a study on 33,500 students and reported that taller students performed better academically than shorter students of the same age (19). Since then, many studies have been carried out examining the association between height and intellectual development. Most of them have shown that taller children tend to score higher in IQ tests. This correlation was observed even after considering confounding factors such as socioeconomic status, race, family size, and income $(11,12,20)$. However, the authors of those studies emphasize that there is no evidence to confirm that an increase in height will itself cause a rise in intelligence. Although both intelligence and height are highly heritable, other factors such as nutrition, cognitive 
Table 5 Multiple linear regression analysis

\begin{tabular}{lccc}
\hline \multirow{2}{*}{ Parameter } & \multicolumn{3}{c}{ Height percentile } \\
\cline { 2 - 4 } & $\beta$ & $\mathrm{SE}$ & $\mathrm{P}^{\mathrm{a}}$ \\
\hline Full scale IQ* & 0.48 & 0.19 & 0.018 \\
Verbal IQ* $_{\text {Nonverbal IQ* }}$ & 0.44 & 0.18 & 0.019 \\
& 0.45 & 0.19 & 0.025 \\
\hline
\end{tabular}

a , adjusted for birth weight, hypothyroidism, and congenital cardiac defect; *, log-transformed values. $\beta$, standardized beta coefficients; SE, standard error; IQ, intelligence quotient.
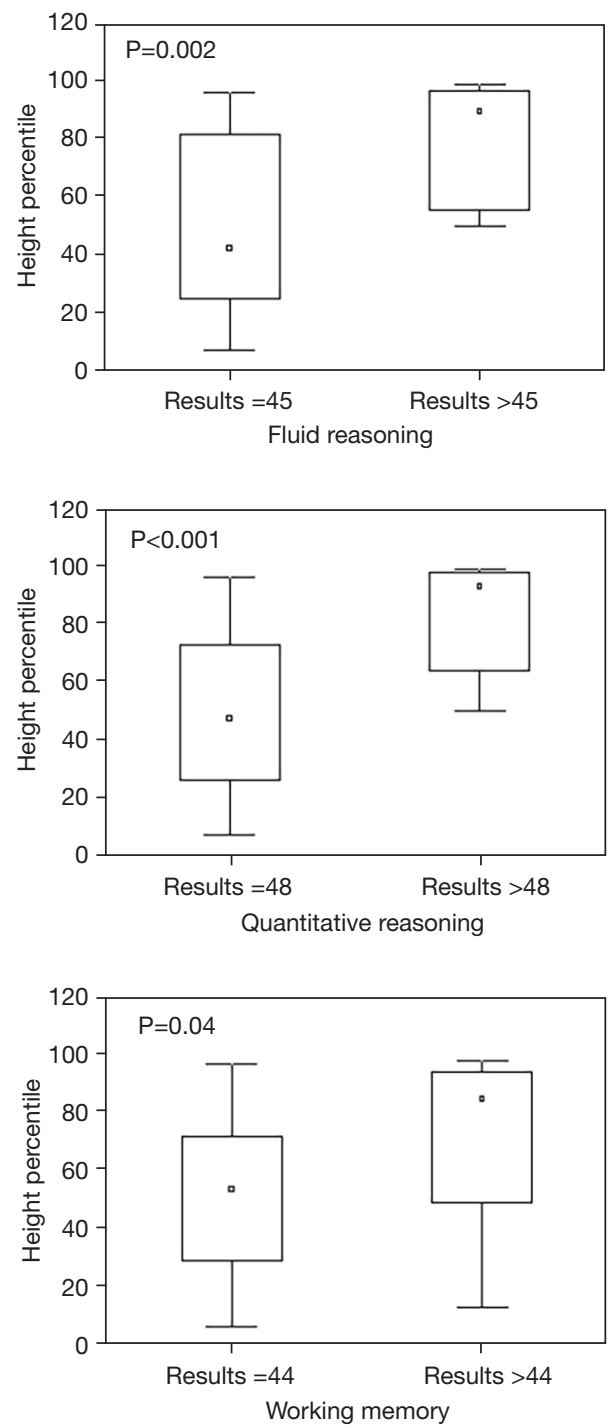

stimulation, diseases, and stress may also influence height as well as IQ. A recent meta-analysis on linear growth and child development in low- and middle-income countries showed that linear growth is positively correlated with cognitive and motor development, especially in the first 2 years of life. This supports the hypothesis that early exposure to malnutrition and infection can restrict linear growth and cause brain development deficits that may persist throughout childhood (21). However, we did not include participants with malnutrition and severe associated
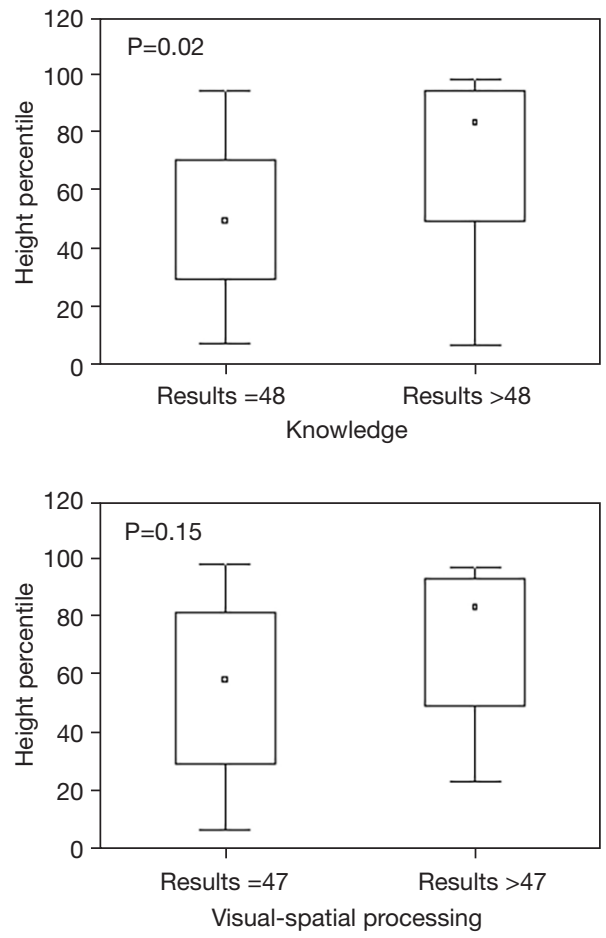
diseases affecting energy balance or growth in this study.

Among the taller children ( $>50$ percentile) included in our study, there were individuals with IQ ranging from 10 to 60 , but the group of shorter children ( $<50$ percentile) had no one with an IQ above 35 (Table 3). This finding suggests that growth is not the only factor that can directly affect IQ, which appears to be consistent with previously reported observations on healthy children.

Growth is a well-known indicator of health during childhood. Chronic heart, renal, and gastrointestinal tract diseases are recognized factors inhibiting linear growth. As mentioned before, many of these are more common in people with DS than in the general population. During the first year of life, growth hormone $(\mathrm{GH})$ influences growth by stimulating the production of insulin-like growth factor I (IGF-1). Impaired growth in children affected by chronic diseases is linked to a state of relative $\mathrm{GH}$ resistance, as indicated by normal or high serum GH, low IGF-1, and low IGF-1-binding protein (19). For nearly 20 years, growth hormone therapy (GHT) has been used in the clinical management of children with chronic kidney disease. Longterm GHT has been shown to induce persistent catchup growth in this population, with a majority of them reaching normal adult height (22). In the DS population, $\mathrm{GH}$ concentration was found to be in normal ranges, but a reduced serum $\mathrm{GH}$ response was observed in the stimulation test (levodopa, clonidine) (23). An Italian study conducted in 2014 assessing the GH-IGF-1 axis in DS children showed that $36 \%$ of the studied population had a low basal level of IGF-1 with a good response to recombinant $\mathrm{GH}$. This suggests that in some DS patients impaired growth can be due to biologically inactive endogenous GH molecule (24).

DS shares many common clinical features with other genetic syndromes such as Prader-Willi syndrome (PWS). Similar to children with chronic kidney disease, children with PWS are also treated by GHT starting from the first year of life. In addition to improving growth velocity and metabolism, early GHT has been shown to promote mental and motor development as well as adaptive functioning in the PWS population $(25,26)$.

The effectiveness of GHT in DS is still being investigated. A few studies have analyzed the effect of GHT in children with DS (27-29). For instance, a study performed on 15 Swedish children with DS (mean age 7.4 months), who received $\mathrm{GH}$ injections daily for 3 years, showed a good response in growth velocity during treatment and a slight improvement in fine motor skills at the age of 3.5 years in comparison to the control group. Although the authors observed no significant difference in the head circumference or mental development of the children at that age, in the follow-up study conducted 15 years after treatment, they noted a greater head circumference and better psychomotor development in the treated group $(30,31)$.

The main strength of this study is that it included children with DS who were presenting with different comorbid diseases that are common in DS patients, which indicates that the studied group is representative of the DS population. It must be mentioned that many of the analyzed children have hypothyroidism and need tRT from early childhood, but this comorbid disease is very commonly observed in DS patients and the exclusion of those children would reduce the generalizability of the study. Additionally, to reduce the possibility of selection bias, we assessed the level of thyroid-stimulating hormone in all patients. Another strength of the study is that it used SB-V, which is one of the most precise tools available in Polish for the assessment of full-scale IQ (range from 10 to 225). This allowed us to disperse the study population and gave credibility to our results. We did not include a control group due to the difficulty in matching the population in terms of comorbidity, and a poorly matched control group could contribute bias into the study. The main limitation of this study is related to the studied population of DS children. Most of the parents were open-minded, cooperative, willing to participate in scientific research, and dedicate more time for their children, as this study was performed on two separate days. This factor had eliminated from the study those children whose parents, for various reasons, could not or did not want to participate. In this light, the studied group of children may not reflect the entire population of children with DS. Another limitation of this study is its relatively small sample size, which is partly due to the lack of a national registry for DS patients.

\section{Conclusions}

The results of the present study suggest that an association exists between the height percentile and IQ of children with DS. However, these should be confirmed by further research with a longitudinal sample of children with DS. Our observations may be valuable in the context of expanding access to GHT in genetic syndromes with short stature. 


\section{Acknowledgments}

The authors thank all participants and their families for taking part in the study. They also thank the Institute of Psychology of the University of Gdańsk. The authors also thank Translmed Publishing Group for professional language editing.

Funding: This work was supported by the Medical University of Gdańsk, under grants Nos. ST 02-0125/07/524 and ST 02-0549/07/455.

\section{Footnote}

Reporting Checklist: The authors have completed the STROBE reporting checklist. Available at https:// tp.amegroups.com/article/view/10.21037/tp-21-424/rc

Data Sharing Statement: Available at https://tp.amegroups. com/article/view/10.21037/tp-21-424/dss

Conflicts of Interest: All authors have completed the ICMJE uniform disclosure form (available at https://tp.amegroups. com/article/view/10.21037/tp-21-424/coif). The authors have no conflicts of interest to declare.

Ethical Statement: The authors are accountable for all aspects of the work in ensuring that the questions related to the accuracy or integrity of any part of the work are appropriately investigated and resolved. The study was conducted in accordance with the Declaration of Helsinki (as revised in 2013). All participants and their parents/ guardians provided written informed consent to participate in the study. All study procedures were reviewed and approved by the Independent Bioethics Committee for Scientific Research at the Medical University of Gdańsk (No. NKBBN/105-96/2016).

Open Access Statement: This is an Open Access article distributed in accordance with the Creative Commons Attribution-NonCommercial-NoDerivs 4.0 International License (CC BY-NC-ND 4.0), which permits the noncommercial replication and distribution of the article with the strict proviso that no changes or edits are made and the original work is properly cited (including links to both the formal publication through the relevant DOI and the license). See: https://creativecommons.org/licenses/by-nc-nd/4.0/.

\section{References}

1. Pulsifer MB. The neuropsychology of mental retardation. J Int Neuropsychol Soc 1996;2:159-76.

2. de Graaf G, Buckley F, Skotko BG. Estimates of the live births, natural losses, and elective terminations with Down syndrome in the United States. Am J Med Genet A 2015;167A:756-67.

3. Tsou AY, Bulova P, Capone G, et al. Medical Care of Adults With Down Syndrome: A Clinical Guideline. JAMA 2020;324:1543-56.

4. Bull MJ; Committee on Genetics. Health supervision for children with Down syndrome. Pediatrics 2011;128:393-406.

5. Korenberg JR, Chen XN, Schipper R, et al. Down syndrome phenotypes: the consequences of chromosomal imbalance. Proc Natl Acad Sci U S A 1994;91:4997-5001.

6. Myrelid A, Gustafsson J, Ollars B, et al. Growth charts for Down's syndrome from birth to 18 years of age. Arch Dis Child 2002;87:97-103.

7. Kułaga Z, Litwin M, Tkaczyk M, et al. Polish 2010 growth references for school-aged children and adolescents. Eur J Pediatr 2011;170:599-609.

8. Roizen NJ, Patterson D. Down's syndrome. Lancet 2003;361:1281-9.

9. Bertapelli F, Pitetti K, Agiovlasitis S, et al. Overweight and obesity in children and adolescents with Down syndromeprevalence, determinants, consequences, and interventions: A literature review. Res Dev Disabil 2016;57:181-92.

10. Karmiloff-Smith A, Al-Janabi T, D'Souza H, et al. The importance of understanding individual differences in Down syndrome. F1000Res 2016;5:eF1000 Faculty Rev-389.

11. Pearce MS, Deary IJ, Young AH, et al. Growth in early life and childhood IQ at age 11 years: the Newcastle Thousand Families Study. Int J Epidemiol 2005;34:673-7.

12. Walker SP, Grantham-Mcgregor SM, Powell CA, et al. Effects of growth restriction in early childhood on growth, IQ, and cognition at age 11 to 12 years and the benefits of nutritional supplementation and psychosocial stimulation. J Pediatr 2000;137:36-41.

13. Sacchi C, Marino C, Nosarti C, et al. Association of Intrauterine Growth Restriction and Small for Gestational Age Status With Childhood Cognitive Outcomes: A Systematic Review and Meta-analysis. JAMA Pediatr 2020;174:772-81. 
14. Lindström L, Wikström AK, Bergman E, et al. Born Small for Gestational Age and Poor School Performance - How Small Is Too Small? Horm Res Paediatr 2017;88:215-23.

15. Chou JH, Roumiantsev S, Singh R. PediTools Electronic Growth Chart Calculators: Applications in Clinical Care, Research, and Quality Improvement. J Med Internet Res 2020;22:e16204.

16. Growth Charts for Children with Down Syndrome. Available online: https://peditools.org/downpedi/ (accessed 17 June 2021).

17. Roid GH, Sajewicz-Radtke U, Radtke BM, et al. Skala Inteligencji Stanford-Binet, Edycja Piąta. Podręcznik interpretacyjny. Przewodnik po zaawansowanej interpretacji wyników SB5. Pracownia Testów Psychologicznych i Pedagogicznych, 2018.

18. Roid G, Jurek P, Olech M, et al. Skale Inteligencji StanfordBinet, Edycja Piąta. Podręcznik techniczny. Pracownia Testów Psychologicznych i Pedagogicznych, 2017.

19. Patel L. Growth and chronic disease. Ann Nestlé 2007;65:129-36.

20. Wilson DM, Hammer LD, Duncan PM, et al. Growth and intellectual development. Pediatrics 1986;78:646-50.

21. Sudfeld CR, McCoy DC, Danaei G, et al. Linear growth and child development in low- and middle-income countries: a meta-analysis. Pediatrics 2015;135:e1266-75.

22. Drube J, Wan M, Bonthuis M, et al. Clinical practice recommendations for growth hormone treatment in children with chronic kidney disease. Nat Rev Nephrol 2019;15:577-89.

23. Castells S, Torrado C, Bastian W, et al. Growth hormone deficiency in Down's syndrome children. J Intellect Disabil Res 1992;36:29-43.

Cite this article as: Kłosowska A, Kuchta A, Ćwiklińska A, Sałaga-Zaleska K, Jankowski M, Kłosowski P, Mański A, Zwiefka M, Anikiej-Wiczenbach P, Wierzba J. Relationship between growth and intelligence quotient in children with Down syndrome. Transl Pediatr 2022;11(4):505-513. doi: 10.21037/ tp-21-424
24. Barreca A, Rasore Quartino A, Acutis MS, et al. Assessment of growth hormone insulin like growth factor-I axis in Down's syndrome. J Endocrinol Invest 1994;17:431-6.

25. Yang A, Choi JH, Sohn YB, et al. Effects of recombinant human growth hormone treatment on growth, body composition, and safety in infants or toddlers with PraderWilli syndrome: a randomized, active-controlled trial. Orphanet J Rare Dis 2019;14:216.

26. Festen DA, Wevers M, Lindgren AC, et al. Mental and motor development before and during growth hormone treatment in infants and toddlers with Prader-Willi syndrome. Clin Endocrinol (Oxf) 2008;68:919-25.

27. Annerén G, Sara VR, Hall K, et al. Growth and somatomedin responses to growth hormone in Down's syndrome. Arch Dis Child 1986;61:48-52.

28. Torrado C, Bastian W, Wisniewski KE, et al. Treatment of children with Down syndrome and growth retardation with recombinant human growth hormone. J Pediatr 1991;119:478-83.

29. Annerén G, Tuvemo T, Carlsson-Skwirut C, et al. Growth hormone treatment in young children with Down's syndrome: effects on growth and psychomotor development. Arch Dis Child 1999;80:334-8.

30. Annerén G, Tuvemo T, Gustafsson J. Growth hormone therapy in young children with Down syndrome and a clinical comparison of Down and Prader-Willi syndromes. Growth Horm IGF Res 2000;10 Suppl B:S87-91.

31. Myrelid Å, Bergman S, Elfvik Strömberg M, et al. Late effects of early growth hormone treatment in Down syndrome. Acta Paediatr 2010;99:763-9. 